\title{
THE PESTICIDES TOXIC IMPACT ON THE HUMAN HEALTH CONDITION AND THE ECOSYSTEM
}

\author{
Venelin Terziev ${ }^{1}$ and Stoyanka Petkova - Georgieva ${ }^{2}$ \\ ${ }^{1}$ Full Member of the Russian Academy of Natural History, Professor, Eng., D.Sc. (National \\ Security), D.Sc. (Economics), D.Sc. (Social Activities), Ph.D., Russian Academy of Natural History, \\ Moscow, Russia, Vasil Levski National Military University, Veliko Tarnovo, Bulgaria University of \\ Rousse, Rousse, Bulgaria, terziev@skmat.com \\ ${ }^{2}$ Associate Professor, Ph.D., University „Prof. d-r Assen Zlatarov” - Bourgas, Bulgaria, \\ s.p.petkova@gmail.com
}

\begin{abstract}
Over the years, pesticides have been accumulated, particularly in the ecosystem of the developing countries. Most of them are with the expiate date of use though constitutes and are a serious threat with its toxic impact on the human health and environment. Besides, the stockpiles of obsolete pesticides are stored in the open air or in inappropriate storage conditions. Containers are often inadequate and leaking or corroded, though contaminated the drinking water sources and irrigation schemes. There are various methods for adequate disposal of obsolete pesticides but are generally costly and require expert knowledge. The Food and Agriculture Organisation (FAO) of the United Nations (UN) is implementing a Programme on Prevention and Disposal of Obsolete in ecosystem of the developing countries to provide them with the adequate tools to sound management of pesticides. The management of pesticides in developing countries need to be improved trough an effective control over the agricultural and public health pesticides, their application in agriculture and public health, the disposal of obsolete stocks and empty pesticide containers, storage facilities, public information, environmental protection, regulation and its enforcement. The present study provides an overview of the disposal of obsolete pesticides in the ecosystem of the developing countries and means of prevention its accumulation in order to decrease their toxic impact on the human health.
\end{abstract}

Keywords: toxic impact, human health condition, pesticides, ecosystem.

\section{INTRODUCTION}

Many pesticides are not biodegradable and due to bioaccumulation, can enter into food chain and ultimately affect human and animal health. Environmental exposure of humans to pesticides through ecosystems may occur during agricultural practices, consumption of food materials or air inhalation etc. Adverse health effects include acute and persistent injury to the nervous system, lung damage, injury to reproductive organs, and dysfunction of the immune and endocrine systems, birth defects and cancer. A better understanding of the patterns of exposure, the links between the animal toxicology and human health effects will improve the evaluation of the risks posed by pesticides to the ecosystem. There is need to educate all stakeholders on 
responsible use of pesticides and proper application of integrated pest management programs, this will positively reflect on human health, biodiversity and ecosystem management and minimize pesticides environmental problems. International conventions such as the Rotterdam Convention, the Chemical Weapon Convention, Stockholm Convention and the Montreal Convention are some of efforts of the international community to address pesticides environmental issues, in all the above convections, efforts are directed either on total ban or restricted use of some classified pesticides (Terziev, Petkova- Georgieva, 2019-a).

\section{THE PESTICIDES TOXIC IMPACT ON THE HUMAN HEALTH CONDITION AND THE ECOSYSTEM}

\section{- Pesticides}

Pesticides are generally defined as substances or mixture of substances for controlling, preventing, destroying, repelling or attacking any biological organism and includes; insecticides, herbicides, fungicide and rodenticides among other chemical substances. Many pesticides in the market fall under what has been described as Persistent Organic Pollutants (POPs). According to the United Nations Environmental Program, (www.chm.pops.int/Convention/POPs), POPs have been defined as organic chemical substances with physical and chemical properties that once released into the environment:

- Remain intact for exceptionally long periods of time;

- Become widely distributed throughout the environment;

- Accumulate in the fatty tissue of living organisms;

- Are toxic to animals- humans and wildlife.

The United Nation Environmental Program further observed that as a result of their releases to the environment over the past several decades due to human activities, these substances are now widely distributed over large regions including those where they have never been used. This extensive contamination of ecosystem has resulted to a sustained exposure of many species for a period of time that span to generations, leading to both acute and chronic toxic effects. Pesticides that are POPs concentrates in living organisms through bioaccumulation and although they are insoluble in water, they are readily absorbed in fatty tissue through food chain and the organism travel with them, as a result, these chemical substances can be found in living organisms far away from their source (www.chm.pops.int/Convention/POPs).

\section{- Ecosystem}

Interdependencies among organizational subunits vary along a continuum. At one end of the ecosystem is a natural unit consisting of all living organisms in an area interacting with all of the non-living physical factors of the environment; it is a completely independent unit of interdependent organisms which share the same habitat. Organisms interact with one another in many ways, including competitive, predatory, parasitic and facilitative ways, such as pollination, seed dispersal and the provision of habitat. These fundamental linkages among organisms and their physical and biological environment constitute an interacting and ever-changing system that is known as an ecosystem. Humans are a component of these ecosystems and depend on the ecosystem properties and on the network of interactions among organisms and within and among ecosystems for sustenance, just like all other species.

As organisms interact with each other and their physical environment, they produce, acquire, or decompose biomass and the carbon-based or organic compounds associated with it. They also move minerals and other chemical substances from the water and soil into and among organisms, and back again into the physical environment in enormously complex relationships where each species has unique requirements for life and each species interacts with both the physical and the biological environment. Recent perturbations, driven principally by human activities, have added greater complexity by changing to a large degree the nature of those environments.

\section{- Movement of Pesticides in the Ecosystem}

The increasing use and disposal of pesticides provide many possible sources of pesticides in the environment. Pesticides which are sprayed can move through the air and may eventually end up in other parts of the ecosystem; these that are applied directly to the soil may be washed off the soil into nearby bodies of surface water or may percolate through the soil to lower soil layers and groundwater. The application of pesticides directly to bodies of water for weed control, or indirectly as a result of leaching, runoff or other routes, may lead not only to build up of pesticides in water, but also may contribute to air 
levels through evaporation (Figure 1).

Once pesticides are released into the environment:

- They may be broken down by the action of sunlight, water, other chemicals or microorganisms and lead to the formation of less harmful products and in some instances more toxic products;

- They may be very resistant to degradation by any means and remain unchanged in the environment for long period of time, move over long distances and can build up in the environment.

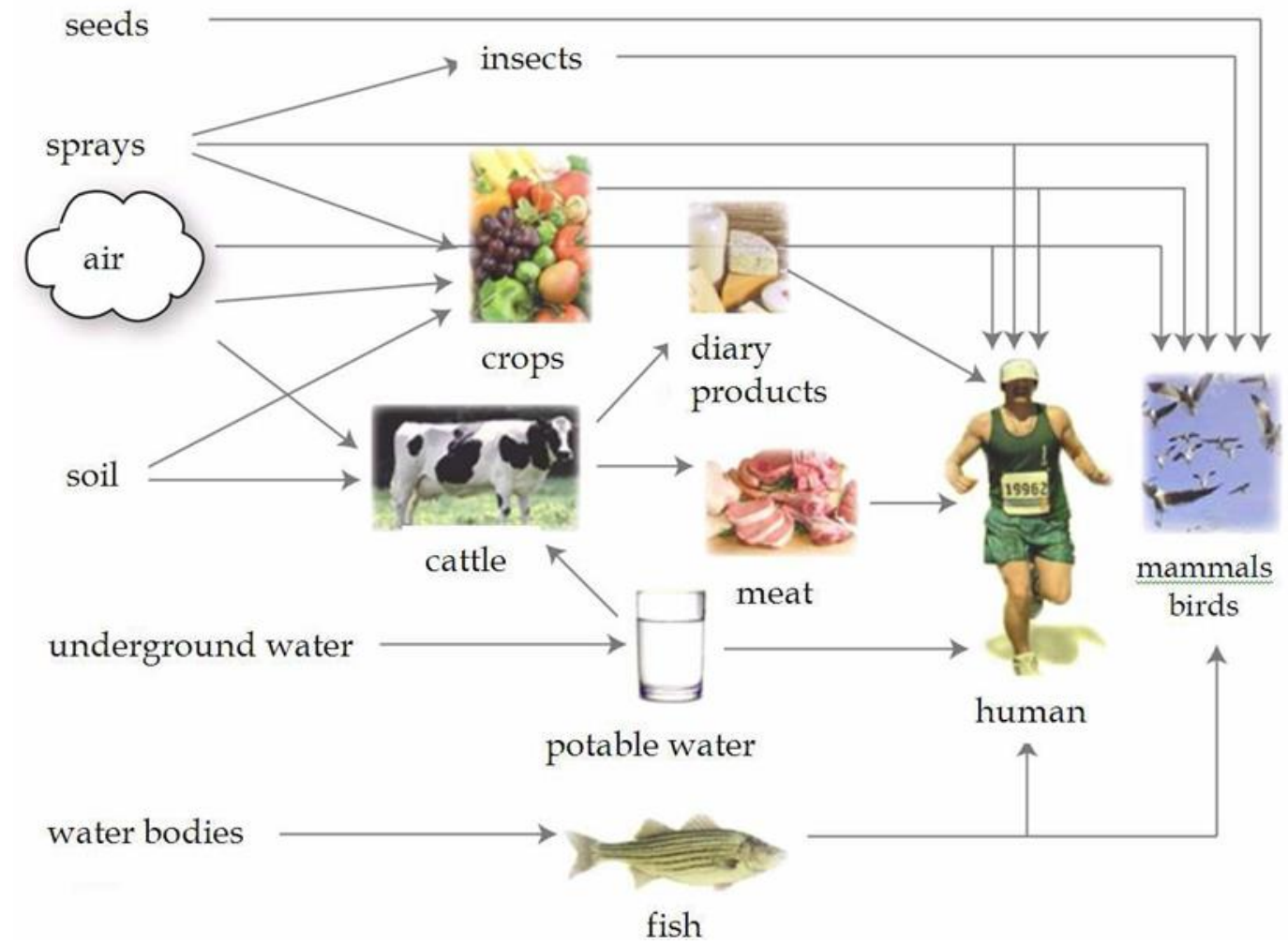

Figure 1. Routes of exposure to pesticides (adapted from WHO, 2003) (2003b).

- Effects of pesticides in the ecosystem

Pesticides are the only group of chemicals that are purposely applied to the environment with the aim to suppress plant and animal pests and to protect agricultural and industrial products. However, the majority of pesticides are not specifically targeting the pest only and during their application they also affect non- target plants and animals, as result therefore repeated application can potentially lead to loss of biodiversity. Many pesticides are not easily degradable, they persist in soil, leach to groundwater and surface water and contaminate widely environment. Depending on their chemical properties they can enter the organism, bio accumulate in food chains and consequently influence also human health. Generally, intensive pesticide application results in several negative effects in the environment that cannot be ignored. Ecological consequences of pesticides can be studied at several levels such as:

- Accidental pesticide contamination of the environment may provide clues about how populations might be affected at the lower recommended use levels.

- Testing of sensitive species to indicate whether new biological or chemical pesticides will likely have side effects.

- Though studies designed to measure the effects of pesticides on ecological parameters such as species diversity, energy flow, decomposition, tropic structure on indicator or monitored species.

- Laboratory experiments performed with individuals, populations, or model ecosystems constructed from combinations of species chosen to represent the numerous components of natural ecosystems.

Generally, with a few exceptions, insecticides are the most toxic pesticides to the environment, followed by fungicides and herbicides. The most hazardous pesticides include those that can be distinguished on the basis of either water or fat solubility. Water soluble compounds are easily transported out of the target area into ground water and streams; fat soluble chemicals are readily absorbed into the food chain, often resulting 
in extended persistence in food chains (Yadav, 2007b).

\section{- Human}

Specific health effect of pesticides on human and other wild animals can include cancer, allergies and hypersensitivity, damage to the central and peripheral nervous systems, reproductive disorders, and disruption of the immune system. Some POPs are endocrine system disrupters thus capable of altering and damaging the hormonal system, the reproductive and the immune systems of those exposed as well as of their offspring; these substances are also thought to have developmental and carcinogenic effects, www.chm.pops.int/Convention/POPs.

The World Health Organization estimates that every year 3 million people experience acute poisoning by organophosphates, (WHO 1990). Over the years many human illnesses and deaths have occurred as a result of exposure to pesticides either intentionally or unintentionally. According to WHO (2003b), pesticide poisoning has been acknowledged as a serious problem in many agricultural communities of low and middle income countries, WHO estimate that of the 900,000 people who die as a result of suicide every year worldwide, about 250,000 of them is as a result of pesticide suicide poisoning. There have also been major accidents involving pesticides that have led to the death or illness of many thousands, one instance occurred in Bhopal, India, where more than 5,000 deaths resulted from exposure to accidental emissions from a pesticide factory (Lorenz \& Eric, 2009).

\section{- Soil microorganisms}

Fungicides were found to be toxic to soil fungi and actinomycetes and caused changes in microbial community structure. Studies have indicated that other bacterial species, such as nitrification bacteria, are very sensitive to pesticides influence, (Liebich et al., 2003). The same studies showed that some organochlorine pesticides suppress symbiotic nitrogen fixation resulting in lower crop yields. It was found that pesticides for example Methyl parathion at levels found in farm soils interfered with leguminous plant symbiotic soil bacteria. This effect is loosely comparable to endocrine disruptive effects of pesticides in human and animals and significantly disrupts nitrogen fixation. As consequence increased dependence on synthetic nitrogenous fertilizer, reduced soil fertility, and unsustainable long-term crop yields has been witnessed. This observation may also explain the trend in the last decades toward stagnant crop yields despite record high use of pesticides and synthetic fertilizers worldwide (Potera, 2007a).

\section{- Invertebrates}

Nematodes, mites and further micro-arthropods, earthworms, spiders, insects and all other small organisms make up the soil food web and enable decomposition of organic compounds and also prey on crop pests. A laboratory experiment in France showed that mixture of insecticides and/or fungicides at different environmental concentrations caused a neurotoxic effect in earthworms. After a long period of exposure or high concentrations, earthworms were physiologically damaged and could not cope with the high toxicity (Schreck et al., 2008). An integrated study in Argentina showed deleterious effect of these pesticides on earthworm population. Earthworms avoided soil with chlorpyrifos their feeding activity and viability were reduced. Chlorpyrifos also caused several adverse effects at cellular level that indicated physiological stress. The study concluded that the effects observed on the avoidance to chlorpyrifos could contribute to earthworm decrease, with the subsequent loss of their beneficial functions to the ecosystem (Casabé et al., 2007).

\section{- Water organisms}

Pesticides can enter fresh water streams directly via spray drift or indirectly via surface runoff. Many pesticides are toxic to water organisms with acute and chronic effects being witnessed in the ecosystem. Downstream drift has been shown for several pesticides such as; organochlorine, organophosphate or insecticides. Neurotoxic insecticides have been found to exhibit the strongest drift-initiating effects on stream-dwelling insects. Moreover, it has been detected that macro invertebrate drift can be induced even by short-term pulse exposures (within 2 hours) at field- relevant concentrations (Relyea, 2003a).

An investigation of pesticides effects on stream macro invertebrate community structure was conducted in France and Finland. It was proved that pesticides stress was associated with a decrease in the relative abundance and number of sensitive species and suggested that the effects may also occur below levels that are commonly thought to be protective (Relyea, 2003a). Other studies have reported toxic effect on aquatic vertebrates by pesticides such as Malathion which is the most commonly applied insecticide around the world and can be legally directly sprayed over aquatic habitats to control the mosquitoes. This study showed that relatively small concentrations of Malathion caused direct and indirect effect on aquatic food chain (Schafer et al., 2007b). 
- Birds

Pesticides had created striking effects on birds, those in the higher trophic levels of food chains, such as bald eagles, hawks, and owls. These birds are often rare, endangered, and susceptible to pesticide residues such as those occurring from the bio concentration of organochlorines insecticides through terrestrial food chains. Pesticides will also kill grain and plant-feeding birds, and the elimination of many rare species of ducks and geese has been reported. Populations of insect-eating birds such as partridges, grouse, and pheasants have decreased due to the loss of their insect food in agricultural fields through the use of insecticides.

There is evidence that birds are continuing to be harmed by pesticide use, for example in the farmland of Britain, populations of different species of birds have declined by millions of breeding individuals between 1979 and 1999. This reduction in bird populations has been found to be associated with times and areas in which pesticides are used (Kerbs et al., 1999). In another example, some types of fungicides used in peanut farming are not only slightly toxic to birds and mammals, but may kill off earthworms, which can in turn reduce populations of the birds and mammals that feed on them (Beketov et al, 2007).

Decline of farmland bird species has been reported over several past decades and has often been attributed to changes in farming practises, such as increased agrochemical inputs, loss of mixture farming or unfarmed structures. Besides lethal and sub lethal effects of pesticides on birds, concern has recently focused on the indirect effects. These effects act mainly via reduction of food supplies. As a consequence, insecticide and herbicide application has led to reduction of chick survival and bird population. Some pesticides can affect birds' reproduction directly, as evidenced by the deleterious effect of the persistent organochlorine insecticides on birds. Eggshell thinning due to the uptake of organochlorine insecticides has been observed in predacious birds (Newton et al., 1986).

\section{- Control of pesticides}

The environmental impact of pesticides can be reduced in several ways, from pollution prevention at source to the treatment of symptoms like unwanted environmental effects. The international community has taken concerted effort to control pesticides pollution of the environment through initiatives such as The Stockholm Convection in which $70 \%$ of the chemicals covered under convention are pesticides, Rotterdam Convection in which $73 \%$ of the chemicals covered are pesticides, Montreal Protocol where fumigant such as carbon tetra chloride is highly restricted while methyl bromide is placed for a phased out total ban and the Chemical Weapons Convection where organophosphates such as Sarin, Soman and Taban are listed as schedule1 chemicals under the convention. Efforts are being directed at complete elimination of some chemical substances, restricted use of some and controlled use of some chemical substances. Different approaches have been witnessed in some cases; different countries taking different stand on a chemical substance. For example, while some countries such as Kenya have imposed a complete ban on the use of DDT and other classified pesticides under restricted use (www.pcpb.or.ke), some countries on the other hand apply restricted application of DDT pesticide as provided for in the Rotherdam Convention.

Generally, the strategies applied in different jurisdictions for the protection of the environment against pesticides covers measures such as:

- Reducing the fundamental need for chemical crop protection by offering alternatives, lowering the disease pressure and the use of pesticides only as required, rather than on a preventive basis. Reducing the use of pesticides will in general also lead to a reduction of the amount of pesticides diffused into the environment;

- Authorizing the use of environmentally safe pesticides only;

- Ensuring the environmentally sound use of pesticides by everyone working with them;

- Taking strict precautions to prevent pesticides from spreading beyond the area treated;

- Reducing the need for chemical crop protection by re-establishing the ecological balance in agroecosystems through preventive measures to reduce the occurrence of a plague or disease and stimulation of research into application of non-chemical alternatives for crop protection.

In addition to human health considerations, pesticides have to be evaluated in line with their behavior in soil and water and for their undesirable effects on both macro and micro-organisms in the environment, this could be done through establishing sets of clearly defined environmentally based criteria through which pesticides or their main metabolites must fulfil before being passed for use or disposal to the ecosystem. These criteria will have to be based on precautionary and ecologically acceptable principles rather than exclusively on the basis of their acute toxicity. 
Some of the environmental problems caused by pesticides are due to negligence which can be overcome by ensuring that everybody handling pesticides does so with due regard for the protection of the environment, for example the development of collection systems for incineration or chemical treatment that has also been taking place. It is obvious that disposal by discharging these highly concentrated waste fluids into surface waters is very dangerous for aquatic ecosystems. Reducing the use of pesticides will generally also lead to a reduction of the amount of pesticides diffused into the environment (Todorov, 2015; Todorov, 2018).

\section{CONCLUSION}

A number of international instruments have been developed that address the aspects of chemical and waste management. The instruments themselves and the infrastructure that supports their implementation are specifically geared towards helping developing countries. However, any country seeking support from donors or intergovernmental agencies to deal with obsolete pesticide disposal and prevention will be expected to ratify and implement the instruments below in their national legislation. The environmental health effect of persistent pesticides in the ecosystem, is clearly great and affect all the components of the ecosystem either directly, indirectly or both, the effects are both chronic a non-chronic and may extend to geographical zones and even to future generations. Both state and non-state actors in the chemical and agricultural industry and even the household should embrace sound practices in the management of pesticides in their daily use of the same. Studies should be extended to find alternatives of toxic persistence pesticides and as much as possible, persistent pesticides should be avoided. Solutions to problems of obsolete and unwanted pesticides stocks are available but are generally costly and require expert technical knowledge. The Food and Agriculture Organization (FAO) is implementing a Programme on Prevention and Disposal of Obsolete in developing countries. Most developing countries are been supported by FAO and other donors to build capacity to sound management of pesticides (Terziev, Petkova- Georgieva, 2019a).

\section{REFERENCE LIST}

Terziev, V., Petkova - Georgieva, S. (2019). The performance measurment system key indicators and the determinants impact on the level of decentralization using as an example a subdivisional unit from the Bulgarian social health and care experience. // Proceedings of SOCIOINT 2019-6th International Conference on Education, Social Sciences and Humanities 24-26 June 2019- Istanbul, Turkey, International Organization Center of Academic Research, Istanbul, Turkey, 2019, pp. 515-524, ISBN: 978-605-82433-6-1.

Terziev, V., Petkova- Georgieva, S. (2019a). A research study of nonlinearity experiencing in the rate of current account deficit to the Bulgarian health and care national product. // Proceedings of SOCIOINT 2019- 6th International Conference on Education, Social Sciences and Humanities 24-26 June 2019Istanbul, Turkey, International Organization Center of Academic Research, Istanbul, Turkey, 2019, pp. 525-533, ISBN: 978-605-82433-6-1.

Beketov, M.A., Schäfer, R.B., Marwitz, A., Paschke, A., Liess, M. (2007). Long-term stream invertebrate community alterations induced by the insecticide: Effect concentrations and recovery dynamics. Science of the Total Environment 405 Casabé, N., Piola, L., Fuchs, J., Oneto, M.L., Pamparato, L., Basack, S., Giménez, R., Massaro, R., Papa, J.C., Kesten, E. (2007): Ecotoxicological Assessment of the Effects of Glyphosate and Chlorpyrifos in an Argentine Soya Field. Journal of soil sediments 7.

Todorov, M. (2018). Recent advances in computational chemistry for identification of ligands for biological receptors: interdisciplinary aspects, Medical Science Pulse 2018 (12) 1, pp. 12-15, DOI: 10.5604/01.3001.0011.6670, ISSN: 2544-1620.

Todorov, M.(2015). Computational tools for prediction of nuclear receptor mediated effects. East. Acad. J., 2015, 1, pp. 46-56, ISSN:2367-7384.

Liebich, J., Schäffer, A., Burauel, P. (2003). Structural and Functional Approach to Studying Pesticides Sideeffects on Specific Soil Functions, Environmental Toxicology and Chemistry.

Lorenz, Eric S. "Potential Health Effects of Pesticides, (2009). Communications and Marketing.

Newton, I., Bogan, J. A. and Rothery, P. (1986): Trends and Effects of Organochlorines Compounds in Sparrow Hawk Eggs, Journal of Application Ecology 23.

Potera, C. (2007a). Agriculture: Pesticides Disrupt Nitrogen Fixation. Environment Health Perspective 115. 
Relyea, R.A. (2003a). Predator Cues and Pesticides: A double Dose of Danger for Amphibians. Ecological Applications 13.

Schafer, R.B., Caquet, T., Siimes, K., Mueller, R., Lagadic, L., Liess, M. (2007b). Effects of Pesticides on Community Structure and Ecosystem Functions in Agricultural Streams of Three Bio geographical Regions in Europe, Science of the Total Environment 382.

Schreck, E., Geret, F., Gontier, L., Treilhou, M. (2008). Neurotoxic Effect and Metabolic Responses Induced by a Mixture of Six Pesticides on the Earthworm, Chemosphere 71.

World Health Organization (2003b). The World Health Report 2003, Shaping the Future, Geneva.

World Health Organization (2004). The Prevention of Mental Disorders: Effective Interventions and Policy Options, Geneva.

Yadav, SK (2007b). Soil Ecology, New Delhi, APH Publishers. 